\title{
Genome characterization of a novel megrivirus-related avian picornavirus from a carnivorous wild bird Western Marsh-harrier (Circus aeruginosus)
}

Ákos Boros ${ }^{\mathrm{a}, \mathrm{b}}$, Péter Pankovics ${ }^{\mathrm{a}, \mathrm{b}}$, Róbert Mátics ${ }^{\mathrm{c}, \mathrm{d}}$, Ádám Adonyi ${ }^{\mathrm{a}}$, Nóra Bolba ${ }^{\mathrm{a}, \mathrm{b}}$, Tung Gia

$$
\text { Phan }^{\mathrm{e}, \mathrm{f}} \text {, Eric Delwart }{ }^{\mathrm{e}, \mathrm{f}} \text {, Gábor Reuter }{ }^{\mathrm{a}, \mathrm{b} *} \text {, }
$$

${ }^{a}$ Regional Laboratory of Virology, National Reference Laboratory of Gastroenteric Viruses, ÁNTSZ Regional Institute of State Public Health Service, Pécs, Hungary

${ }^{\mathrm{b}}$ Department of Medical Microbiology and Immunology, Medical School, University of Pécs, Pécs, Hungary

${ }^{\mathrm{c}}$ Hungarian Nature Research Society, (HuNaReS), Ajka, Hungary

${ }^{\mathrm{d}}$ Department of Pathophysiology, University of Pécs Medical Center, Hungary

${ }^{\mathrm{e}}$ Blood Systems Research Institute, San Francisco, CA, USA and

${ }^{\mathrm{f}}$ University of California, San Francisco, CA, USA

Running title: Novel harrier picornavirus in Hungary ${ }^{1}$

* Address for correspondence:

Dr Gábor Reuter

Department of Medical Microbiology and Immunology University of Pécs

H-7624 Szigeti út 12. Pécs, Hungary

Telephone: +36 (72) 536252

Fax: +36 (72) 536253

Email: reuter.gabor@gmail.com

\footnotetext{
${ }^{1}$ The GenBank[/EMBL/DDBJ] accession number for the study sequence: KY488458
} 


\begin{abstract}
In this study, the complete genome of novel picornavirus called harrier picornavirus 1 (HaPV-1) strain harrier/MR-01/HUN/2014 (KY488458) was sequenced and analysed from a cloacal sample of a threatened, carnivorous wild bird Western Marsh-harrier (Circus aeruginosus). HaPV-1 was detectable from 2 of the 3 samples from harriers. HaPV-1 is phylogenetically related to the megriviruses (genus Megrivirus) from domestic chicken, turkey and duck showing similar genome organization pattern and has an avian picornaviruslike "Unit A" motif in 3' UTR. Unlike the type-IV IRES of megriviruses HaPV-1 is predicted to contain a type-II-like IRES suggesting modular exchange of IRES elements between picornavirus genomes.
\end{abstract}




\section{Main text}

The small RNA viruses of family Picornaviridae are currently classified into 54 officially accepted species grouped into 31 genera, with a growing number of unassigned picornaviruses awaiting final classification (www.picornaviridae.com) [1,2]. The singlestranded, positive sense RNA (+ssRNA) genomes of picornaviruses predominantly share the same genome layout: $5^{\prime}$ internal ribosomal entry site (IRES) followed by a single open reading frame (ORF), a 3' untranslated region (UTR) and a poly-adenine (poly-A) tail, although the presence of an intergenic IRES is also known among certain picornaviruses $[3,4]$. Most of the picornavirus IRES-es could be classified into five types (IRES type-I to V) $[5,6]$. Within each IRES group, the predicted RNA secondary structure is considerably more conservative than the primary nucleotide sequence [7]. The ORF encodes a single polyprotein which contains the P1 structural (capsid) proteins of VP0 (or VP4-VP2)-VP3-VP1 followed by the P2 and P3 non-structural proteins of 2A-C and 3A-D [3]. The 3' UTRs can contain conserved motifs such as the "barbell-like" structure of avian and mammal +ssRNA viruses or the repetitive "Unit A" motifs exclusively presented among avian picornaviruses [8].

To our current knowledge members of family Picornaviridae are only capable of infecting vertebrate hosts including birds. The majority of the presently known avian picornaviruses belong to five phylogenetic clusters; one of them is the megrivirus cluster [8]. Members of the megrivirus cluster currently includes the turkey megriviruses (also known as turkey hepatitis virus - THV) of genus Megrivirus, the unassigned chicken and duck megriviruses, the pigeon mesiviruses, the poeciviruses of songbirds and the recently identified geese megriviruses. These viruses may cause subclinical infections but could also be associated with serious syndromes such as hepatitis, proventriculitis or keratin disorders of the beaks [8-16]. According to the results of sequence analyses the evolution of chicken and turkey megriviruses as well as the duck and geese megriviruses may have involved at least one interspecies recombination event $[8,12,16]$. All the members of the megrivirus cluster possess 
a type-IV-like IRES with the exception of poeciviruses with an undetermined IRES type $[8,10,15,16]$. The genomes of mesiviruses as well as the chicken, turkey and geese megriviruses presumably contains multiple (up to five) 2A peptides as well as a relatively long 3' UTR ranging between 329 - 641 nt containing repetitive "Unit A" motifs $[8,13,16]$.

The majority of the known avian picornaviruses have been identified from domesticated birds (chicken, turkey, duck, quail and goose) while the number of avian picornaviruses from wild birds, especially carnivorous birds is still low [8]. Here we report the first complete genome of a novel picornavirus called harrier picornavirus 1 (HaPV-1) from a threatened, carnivorous bird called Western Marsh-harrier (Circus aeruginosus) which showed phylogenetic relationship to the megriviruses. HaPV-1 shows a 3-4-4 genome organization pattern with two presumed 2A protein-coding genome regions and a long 3' untranslated region (UTR) with a megrivirus-like organization (multiple repeated "Unit A" motif followed by an AUG-rich region) [8] but unlike megriviruses it possesses a type-II-like IRES.

A single cloacal sample (MR-01) was collected from an apparently healthy adult Western Marsh-harrier (Circus aeruginosus) from Pécs, Hungary in August 2014. The sample was collected by qualified ornithologists with valid permission (National Inspectorate for Environment, Nature and Water: 14/3858-9/2012). The sample was subjected to a viral metagenomic analysis using sequence independent random RT-PCR amplification of viralparticle protected nucleic acids. A viral cDNA library was constructed using ScriptSeqTM v2 RNA-Seq Library Preparation Kit (Epicentre) and sequenced by the Miseq Illumina platform, as described previously [10]. For the determination of the complete picornavirus genome and for the verification of the contigs long-range and conventional RT-PCR, 5'/3' rapid amplification of cDNA ends (RACE) and dye-terminator sequencing methods were used as described previously $[17,18]$. The HaPV-1 contigs served as templates for the virus-specific PCR primer design. The coverage of the contigs was determined and visualized by the UGENE software ver.1.25 [19]. The pairwise alignments and identity calculations of the 
amino acid (aa) sequences were completed by the BioEdit software ver.7.1.3.0 using the inbuilt ClustalW algorithm. The aa alignments for the phylogenetic trees and cleavage site analyses were generated using the MUSCLE algorithm. The potential proteolytic cleavage sites were predicted by the analysis of pairwise aa alignments with the closest sequences. The Neighbor-Joining amino acid phylogenetic trees were constructed using Poisson correction method of MEGA software ver. 6.06. Bootstrap (BS) values (based on 1000 replicates) for each node are shown if BS $>50 \%$. The secondary RNA structure of the presumed IRES region was predicted by the Mfold program and visualized using VARNA ver.3.9 and CorelDRAW ver.12. For epidemiological investigations generic primer pair was designed to the $3 \mathrm{D}^{\mathrm{RdRp}}$ genome region of HaPV-1 (HaPV-Screen-F: 5' - AAT GGA TAT GGT KTK ATG GA -3' and HaPV-Screen-R: 5' - TCA TCA CCA TAR CAR ATC CA - 3'). These primers were used for screening of HaPV-1-related viruses in the available cloacal samples $(\mathrm{N}=24)$ collected from apparently healthy carnivorous birds of additional Western Marsh-harrier (Circus aeruginosus, $\mathrm{N}=2$ ), Common buzzard (Buteo buteo, $\mathrm{N}=1$ ), Common kestrel (Falco tinnunculus, N=9), red-footed falcon (Falco vespertinus, N=5), Eurasian sparrowhawk (Accipiter nisus, $\mathrm{N}=1$ ) and little owl (Athene noctua, $\mathrm{N}=6$ ) collected by qualified ornithologists with valid permission.

From the analyzed sample (MR-01), a total of 1516 sequences (singletons and contigs) showing similarity to viruses were obtained (BLASTx cut-off E score $\leq 10^{-10}$ ) after de novo assembly from 30.949.340 total initial reads. Detected sequences were originated from viruses of family Astroviridae (N=673), Picornaviridae (N=472), Phycodnaviridae $(\mathrm{N}=72)$, Podoviridae ( $\mathrm{N}=63)$, Parvoviridae $(\mathrm{N}=53)$, Mimiviridae $(\mathrm{N}=37)$, Reoviridae $(\mathrm{N}=16)$, Microviridae $(\mathrm{N}=16)$, Circoviridae $(\mathrm{N}=5)$, and unclassified $(\mathrm{N}=109)$ virus families. The 472 picornavirus-related sequence reads were assembled into 3 contigs covering $\approx 75 \%$ of the harrier picornavirus genome. The contig 1 and 3 show $40 \%$ and $46 \%$ amino acid (aa) identity to Duck megrivirus 1 (KC663628) while the contig 2 shows $38 \%$ aa identity to Pigeon 
mesivirus 2 (KC811837) identified as the closest match using NCBI's BLASTx search. The coverage and the positions of the contigs are seen in Figure 1a (Fig. 1A). The complete genome of the HaPV-1 was determined using different RT-PCR methods. The 8541-nt-long complete genome of HaPV-1 strain harrier/MR-01/HUN/2014 (KY488458) was predicted to have a 3-4-4 genome organization pattern: 5'UTR-P1(VP0-VP3-VP1)-P2(2A1-2A2-2B-2C)P3(3A-3B-3C-3D)-3'UTR (Fig. 1b). The presumed P5-P1' proteolytic cleavage sites together with the length of the genome regions were shown in Fig. 1B.

The predicted length of the 5' UTR of HaPV-1 was $833 \mathrm{nt}$ based on the presence of the first in-frame AUG initiation codon found in Kozak-context (GagAuaA ${ }_{735} \underline{\mathrm{UGG}}$, conserved nts are in uppercase, start codon is underlined). The stop codon of the presumed ORF is located between nt positions $8289-8291$ which is followed by a $250 \mathrm{nt}$-long 3' UTR. According to the results of BlastN search, high (85\%) sequence identity was found between the 5' UTR (from nt pos. 604 to 690) of the study strain and the 5' UTR (between nt pos. 474 and 553) of turkey avisivirus strain USA-IN1 (KC614703) which region contained the domain $\mathrm{J}$ and $\mathrm{K}$ of the type-II-like IRES of avisiviruses (Fig. 1C) [20]. The predicted secondary structure of the 5'UTR IRES (from nt position 233 to 757, Fig 1c) of HaPV-1 revealed the presence of five conserved domains designated as domain $\mathrm{H}, \mathrm{I}, \mathrm{J}, \mathrm{K}$ and $\mathrm{L}$ which show structural similarity to the five major core domains of $\mathrm{H}$ to $\mathrm{L}$ identified in the type-II IRES of encephalomyocarditis virus (EMCV, genus Cardiovirus) [21]. Furthermore beside the similar domain structure, the binding sites of pyrimidine tract binding protein (PTB) and translation initiation factor eIF4G as well as conserved motifs like GNRA tetraloop (Stemloop A) and loop B identified in EMCV-IRES are all recognizable in the IRES of the study strain $[3,7,22]$ (Fig. 1C).

The 3' UTR of HaPV-1 contained two consecutively repeated conserved sequence motifs called "Unit A" which were identified first among chicken and turkey megriviruses and later among phylogenetically distant chicken oriviruses (Fig. 1D) [13,23]. The repeated 
56/55-nt-long UnitA sequences shows $89 \%$ nt identity to each other. The "Unit A" sequence repeat was followed by an 83 -nt-long AUG-rich region where the cytosine content was $9 \%$ (data not shown).

The single ORF of HaPV-1 could be divided into P1 (2337 nt; 779 aa), P2 (2511 nt; 837 aa) and P3 (2610 nt; 869 aa) regions. The P1 region as well as the most conservative 2C, and $3 \mathrm{CD}$ proteins show the highest sequence identity to different megri-, and mesivirus strains (Table 1). According to the results of pairwise alignments of HaPV-1 and the closest sequence relatives of megriviruses and related viruses the genome of HaPV-1 does not contain a recognizable Leader protein or a VP4 $\downarrow$ VP2 cleavage site, therefore the P1 genome region presumed to encodes only three capsid proteins (VP0, VP3 and VP1) similar to the megri-, and mesiviruses. The VP0 contains no identifiable N-terminal myristoylation motif (GxxxS/T, $x=$ variable aa). The P2 genome region predicted to encode four $(2 \mathrm{~A} 1,2 \mathrm{~A} 2,2 \mathrm{~B}$ and 2C) mature peptides. The 123 -aa-long $2 \mathrm{~A} 1$ peptide contains none of the currently identified 2A motifs of DxExNPGP ("ribosomal-skipping”), GxxGxGKS of P-loop NTPase-type 2A, chymotrypsin-like protease motifs or the Hbox/NC motifs. However, based on the presence of conserved sequence motifs (Fig 1B) the 181-aa-long 2A2 peptide belongs to the H-box/NCtype $2 \mathrm{~A}$ peptide group similar as the $2 \mathrm{~A} 2$ peptides of pigeon mesiviruses and the $2 \mathrm{~A} 3$ peptides of megriviruses $[8,24]$. The $2 \mathrm{C}$ protein of the study strain predicted to contain all three functional motifs (A-C) of viral NTP-binding proteins therefore it is most likely belongs to the class III helicases (Fig. 1B) [25]. The P3 genome region predicted to encodes four (3A3B-3C-3D) viral peptides. The single $3 \mathrm{~B}^{\mathrm{VPg}}$ peptide of HaPV-1 contains a conservative $\mathrm{Y}$ (tyrosine) at the $3^{\text {rd }}$ position similar as the VPg-s of other picornaviruses [3]. All of the currently known conserved motifs of picornaviral 3C proteinase and 3D RNA-dependent RNA polymerase (RdRp) are recognizable in the corresponding genome regions of the study sequence (Fig. 1B) [26]. 
The P1, 2C and 3CD phylogenetic trees show distant relationship of HaPV-1 with the members of megrivirus phylogenetic cluster (Fig. 2).

Using generic HaPV-1 $3 \mathrm{D}^{\mathrm{RdRp}}$ primers only one sample collected from an additional Western Marsh-harriers was RT-PCR positive from the available cloacal samples $(\mathrm{N}=24)$ collected from apparently healthy carnivorous birds. The $661-n t-l o n g ~ 3 \mathrm{D}^{\mathrm{RdRp}}$ region shows 96\% nucleotide identity to the corresponding part of HaPV-1 strain harrier/MR-01/HUN/2014 (KY488458).

In this study, using metagenomic and RT-PCR methods, the complete genome of a novel harrier picornavirus 1 (harrier/MR-01/HUN/2014, KY488458) was determined and analyzed in detail. HaPV-1 shows similar genomic architecture with a probably multicistronic 2A genome region, common 3'UTR sequence motifs (Unit A followed by an AUG-rich region) and distant phylogenetic relationship to the related avian picornaviruses of the megrivirus cluster.

While the presence of type-IV-like IRES is predominant among the members of the megrivirus cluster $[8,12,16]$ until then the 5 , UTR of HaPV-1 is predicted to contain an IRES which is not belong to the type-IV group. The IRES of HaPV-1 shows the highest sequence identity to a type-II-like IRES which could be a trace of a past recombination event between the ancestors of HaPV-1 and a currently unknown picornavirus with type-II IRES. The presence of other genomic rearrangements was also suspected during the evolution of related megriviruses $[12,13,16]$. The different IRES-types of phylogenetically related picornaviruses are not unprecedented. Similar modular exchanges of IRES domains are suspected during the diverging evolution of avihepato- (type-IV-IRES) and avisiviruses (type-II-IRES) or the porcine kobuviruses (type-IV-IRES) and Aichi viruses (type-V-IRES) of genus Kobuvirus [6,20]. The similar genomic architecture of the 3' UTRs of HaPV-1 and chicken-, turkey megriviruses, pigeon mesiviruses and chicken oriviruses ("Unit A" repeats followed by an AUG-rich region) suggests the advantageous role of this structure during the genome 
replication of these avian picornaviruses [8,23,27]. The presence of repetitive "Unit A" motifs in the 3' UTR of HaPV-1 which motif is exclusively present among avian picornaviruses and the constant phylogenetic relationship of $\mathrm{HaPV}-1$ to the avian picornaviruses of the megrivirus cluster as well as the presence of a $\mathrm{HaPV}$ in a second cloacal sample of an additional Western Marsh-harrier suggest a non-dietary origin of HaPV-1 [8]. Based on the current guidelines of the ICTV Picornaviridae Study Group (http://www.picornastudygroup.com/definitions/genus_definition.htm) a picornavirus belongs to a novel genus if the amino acid differences of the orthologous proteins exceeding $66 \%$ of $\mathrm{P} 1$ and $64 \%$ of $2 \mathrm{C}, 3 \mathrm{C}$ and $3 \mathrm{D}$ compared to the other members of the known picornavirus genera. Based upon the aa identity values (Table 1) HaPV-1 most likely belong to the genus Megrivirus. To our current knowledge HaPV-1 is the first avian picornavirus from a carnivorous wild bird and belongs to the megrivirus phylogenetic cluster, indicating the common presence of megrivirus-related viruses among birds. This could be an important knowledge related to the evolution, host species reservoir and distribution of megrivirus-like viruses. Although the study virus was identified from cloacal samples of apparently healthy harriers, the role of this virus in the development of any manifested symptoms remains to be elucidated considering that certain members of the megrivirus cluster i.e. chicken and turkey megriviruses, chicken proventriculitis virus and poeciviruses - beside subclinical infections have been associated with various diseases [9,12-15]. The characterization of (picorna)viruses of threatened wild birds like the Western Marsh-harrier (member of The IUCN Red List of Threatened Species) could help us to explore the risk factors endangering these bird populations [28].

\section{Acknowledgements}

This work was supported by grants from the Hungarian Scientific Research Fund (NKFIH/OTKA K111615), by the Hungarian Nature Research Society and by NHLBI R01- 
HL105770. Á.B was supported by the European Union and the State of Hungary, co-financed by the European Social Fund in the framework of TÁMOP 4.2.4.A/ 2-11/1-2012-0001 'National Excellence Program'. Á.B. and P.P. are supported by the János Bolyai Research Scholarship of the Hungarian Academy of Sciences.

\section{Compliance with Ethical Standards}

Funding: This study funded by Hungarian Scientific Research Fund (OTKA/NKFIH K111615), by the Hungarian Nature Research Society and by NHLBI R01-HL105770.

Conflict of interest: The authors declare that they have no conflict of interest.

Ethical approval: All applicable international, national, and/or institutional guidelines for the care and use of animals were followed. 


\section{References}

1. Knowles NJ, Hovi T, Hyypiä T, King AMQ, Lindberg AM, Pallansch MA et al. (2012) Picornaviridae. In King, AMQ, Adams MJ, Carstens EB, Lefkowitz EJ, editors. Virus Taxonomy: Classification and Nomenclature of Viruses: Ninth Report of the International Committee on Taxonomy of Viruses, San Diego: Elsevier, pp.855-880.

2. Adams MJ, Lefkowitz EJ, King AMQ, Harrach B, Harrison RL, Knowles NJ et al. (2016) Ratification vote on taxonomic proposals to the International Committee on Taxonomy of Viruses. Arch Virol 161:2921-2949.

3. Palmenberg A, Neubauer D, Skern T (2010) Chapter 1: Genome organization and encoded proteins, p 3-17. In: Ehrenfeld E, Domingo E, Roos RP, editors. The Picornaviruses. ASM Press, Washington, DC.

4. Woo PC, Lau SK, Choi GK, Huang Y, Teng JL, Tsoi HW et al., (2012) Natural occurrence and characterization of two internal ribosome entry site elements in a novel virus, canine picodicistrovirus, in the picornavirus-like superfamily. J Virol 86:2797-2808.

5. Hellen CUT, de Breyne S (2007) A distinct group of Hepacivirus/Pestivirus-like internal ribosomal entry sites in members of diverse picornavirus genera: evidence for molecular exchange of functional noncoding RNA elements by recombination. J Virol 81:5850-5863.

6. Sweeney TR, Dhote V, Yu Y, Hellen CUT (2012) A distinct class of internal ribosomal entry site in members of the Kobuvirus and proposed Salivirus and Paraturdivirus genera of the Picornaviridae. J Virol 86:1468-1486.

7. Belsham GJ, Jackson RJ (2000) Translation initiation on picornavirus RNA. In: Sonenberg N, Hershey JWB, Mathews MB, editors. Translational Control of Gene Expression. Cold Spring Harbor Laboratory Press, Cold Spring Harbor, NY, pp. 869-890. 
8. Boros A, Pankovics P, Reuter G (2014) Avian picornaviruses: molecular evolution, genome diversity and unusual genome features of a rapidly expanding group of viruses in birds. Infect Genet Evol 28:151-166.

9. Honkavuori KS, Shivaprasad HL, Briese T, Street C, Hirschberg DL, Hutchison SK, Lipkin WI (2011) Novel picornavirus in turkey poults with hepatitis, California, USA. Emerg Infect Dis $17: 480-487$.

10. Phan TG, Vo NP, Boros A, Pankovics P, Reuter G, Li OTW, Wang C, Deng X, Poon LLM, Delwart E (2013) The viruses of wild pigeon droppings. PLoS ONE 8 (9):e72787.

11. Liao Q, Zheng L, Yuan Y, Shi J, Zhang D (2014) Genomic characterization of a novel picornavirus in Pekin ducks. Vet Microbiol 172:78-91.

12. Lau SK, Woo PC, Yip CC, Li KS, Fan RY, Bai R, Huang Y, Chan KH, Yuen KY (2014) Chickens host diverse picornaviruses originated from potential interspecies transmission with recombination. J Gen Virol 95:1929-1944.

13. Boros A, Pankovics P, Knowles NJ, Nemes C, Delwart E, Reuter G (2014) Comparative complete genome analysis of chicken and turkey megriviruses (family Picornaviridae): long 3' untranslated regions with a potential second open reading frame and evidence for possible recombination. J Virol 88:6434-6443.

14. Kim H, Yoon S, Lee H, Kwon Y (2015) Identification of a picornavirus from chickens with transmissible viral proventriculitis using metagenomic analysis. Arch Virol 160: 701709.

15. Zylberberg M, Van Hemert C, Dumbacher JP, Handel CM, Tihand T, DeRisi JL (2016) Novel picornavirus associated with avian keratin disorder in Alaskan birds. mBio 7(4):e00874-16. 
16. Wang F, Liang T, Liu N, Ning K, Yu K, Zhang D (2017) Genetic characterization of two novel megriviruses in geese. J Gen Virol doi: 10.1099/jgv.0.000720. PubMed PMID: 28141510.

17. Boros A, Pankovics P, Simmonds P, Reuter G (2011) Novel positive-sense, singlestranded RNA (+ssRNA) virus with di-cistronic genome from intestinal content of freshwater carp (Cyprinus carpio). Plos One 6:e29145.

18. Boros A, Pankovics P, Knowles NJ, Reuter G (2012) Natural interspecies recombinant bovine/porcine enterovirus in sheep. J Gen Virol 93:1941-1951.

19. Okonechnikov K, Golosova O, Fursov M, (2012) the UGENE team. Unipro UGENE: a $\begin{array}{llll}\text { unified bioinformatics } & \text { toolkit. } & \text { Bioinformatics } & 28 \text { : }\end{array}$ doi:10.1093/bioinformatics/bts091

20. Boros A, Nemes C, Pankovics P, Kapusinszky B, Delwart E, Reuter G (2013) Genetic characterization of a novel picornavirus in turkeys (Meleagris gallopavo) distinct from turkey galliviruses and megriviruses and distantly related to the members of the genus Avihepatovirus. J Gen Virol 94:1496-1509.

21. Yu Y, Abaeva IS, Marintchev A, Pestova TV, Hellen CUT (2011) Common conformational changes induced in type 2 picornavirus IRESs by cognate trans-acting factors. Nucleic Acids Res 39:4851-4865.

22. Kaminski A, Hunt SL, Patton JG, Jackson RJ (1995) Direct evidence that polypyrimidine tract binding protein (PTB) is essential for internal initiation of translation of encephalomyocarditis virus RNA. RNA 1:924-938.

23. Boros A, Pankovics P, Adonyi A, Phan TG, Delwart E, Reuter G (2014) Genome characterization of a novel chicken picornavirus distantly related to the members of genus 
Avihepatovirus with a single $2 \mathrm{~A}$ protein and a megrivirus-like 3' UTR. Infect Genet Evol 28:333-338.

24. Hughes PJ, Stanway G (2000) The 2A proteins of three diverse picornaviruses are related to each other and to the H-rev107 family of proteins involved in the control of cell proliferation. J Gen Virol 81:201-207.

25. Gorbalenya AE, Koonin EV, Wolf YI (1990) A new superfamily of putative NTP-binding domains encoded by genomes of small DNA and RNA viruses. FEBS Lett 262:145-148.

26. Gorbalenya AE, Donchenko AP, Blinov V M, Koonin EV (1989) Cysteine proteases of positive strand RNA viruses and chymotrypsin-like serine proteases. A distinct protein superfamily with a common structural fold. FEBS Lett 243:103-114.

27. Rohll JB, Moon DH, Evans DJ, Almond JW (1995) The 3' untranslated region of picornavirus RNA: features required for efficient genome replication. J Virol 69:7835-7844.

28. BirdLife International. 2016. Circus aeruginosus. The IUCN Red List of Threatened Species 2016: e.T22695344A93503491. http://dx.doi.org/10.2305/IUCN.UK.20163.RLTS.T22695344A93503491.en. Downloaded on 20 January 2017. 


\section{Table 1}

Pairwise amino acid sequence identities between the P1, 2C and 3CD proteins of HaPV-1 strain harrier/MR-01/HUN/2014 (KY488458) compared to the representative members of the 35 officially recognized and 11 candidate picornavirus genera. Boldface and underlined numbers indicate the highest levels of amino acid identities.

\begin{tabular}{|c|c|c|c|c|c|}
\hline Genus & Type/virus name & Accession Number & P1 & $2 \mathrm{C}$ & 3CD \\
\hline "Aalivirus" & Duck picornavirus GL/12 & KJ000696 & $14.7 \%$ & $24.5 \%$ & $21.2 \%$ \\
\hline Ampivirus & Ampivirus A1 & KP770140 & $13.8 \%$ & $17.7 \%$ & $19.0 \%$ \\
\hline Aphthovirus & Foot-and-mouth disease virus 1 & AF308157 & $15.3 \%$ & $29.2 \%$ & $28.0 \%$ \\
\hline Aquamavirus & Aquamavirus A1 & EU142040 & $15.1 \%$ & $24.0 \%$ & $18.9 \%$ \\
\hline Avihepatovirus & Duck hepatitis A virus 1 & DQ226541 & $15.3 \%$ & $24.6 \%$ & $21.5 \%$ \\
\hline Avisivirus & Avisivirus A1 & KC465954 & $14.4 \%$ & $24.4 \%$ & $21.7 \%$ \\
\hline Cardiovirus & Encephalomyocarditis virus 1 & M81861 & $17.4 \%$ & $26.5 \%$ & $26.6 \%$ \\
\hline Cosavirus & Cosavirus A1 & FJ438902 & $16.3 \%$ & $25.4 \%$ & $25.5 \%$ \\
\hline "Crohivirus" & Crohivirus 1 & AB937989 & $16.2 \%$ & $25.8 \%$ & $22.2 \%$ \\
\hline Dicipivirus & Cadicivirus A1 & JN819202 & $17.0 \%$ & $27.4 \%$ & $31.4 \%$ \\
\hline Enterovirus & Poliovirus 1 & V01149 & $14.1 \%$ & $29.7 \%$ & $25.6 \%$ \\
\hline Erbovirus & Equine rhinitis B virus 1 & X96871 & $16.0 \%$ & $26.3 \%$ & $29.6 \%$ \\
\hline Gallivirus & Gallivirus A1 & JQ691613 & $14.2 \%$ & $28.9 \%$ & $32.0 \%$ \\
\hline Harkavirus & Falcovirus A1 & KP230449 & $15.8 \%$ & $22.3 \%$ & $21.1 \%$ \\
\hline Hepatovirus & Hepatitis A virus 1 & M14707 & $13.7 \%$ & $23.8 \%$ & $20.2 \%$ \\
\hline Hunnivirus & Hunnivirus A1 & JQ941880 & $19.1 \%$ & $24.1 \%$ & $28.4 \%$ \\
\hline Kobuvirus & Aichivirus A1 & AB010145 & $15.2 \%$ & $29.1 \%$ & $35.5 \%$ \\
\hline Kunsagivirus & Kunsagivirus A1 & KC935379 & $13.3 \%$ & $24.9 \%$ & $20.3 \%$ \\
\hline "Lesavirus" & Lesavirus 1 & KM396707 & $19.3 \%$ & $23.5 \%$ & $27.1 \%$ \\
\hline Limnipivirus & Limnipivirus B1 & KF306267 & $14.2 \%$ & $17.3 \%$ & $21.4 \%$ \\
\hline "Livupivirus" & Livupivirus 1 & KX463670 & $16.0 \%$ & $17.7 \%$ & $32.8 \%$ \\
\hline \multirow{3}{*}{ Megrivirus } & Melegrivirus A1 (THV-1) & HM751199 & $37.7 \%$ & $53.5 \%$ & $45.6 \%$ \\
\hline & THV-1 (B407) & KF961188 & $\underline{38.1 \%}$ & $52.6 \%$ & $45.5 \%$ \\
\hline & THV-1 (0091.1) & HQ189775 & $37.9 \%$ & $53.2 \%$ & $45.6 \%$ \\
\hline \multirow{10}{*}{$\begin{array}{l}\text { Unassigned } \\
\text { megrivirus- } \\
\text { related } \\
\text { picornaviruses }\end{array}$} & Chicken proventriculitis virus 1 & KJ690629 & $33.9 \%$ & $51.7 \%$ & $45.9 \%$ \\
\hline & Chicken picornavirus 4 & KF979335 & $36.6 \%$ & $52.0 \%$ & $45.8 \%$ \\
\hline & Chicken picornavirus 5 & KF979336 & $34.9 \%$ & $52.3 \%$ & $45.6 \%$ \\
\hline & Chicken megrivirus 1 (B21) & KF961186 & $33.7 \%$ & $51.7 \%$ & $46.1 \%$ \\
\hline & Chicken megrivirus 1 (CHK-IV) & KF961187 & $33.7 \%$ & $51.7 \%$ & $46.1 \%$ \\
\hline & Duck megrivirus 1 & KC663628 & $36.2 \%$ & $54.4 \%$ & $48.4 \%$ \\
\hline & Pigeon mesivirus 2 & KC811837 & $35.7 \%$ & $52.1 \%$ & $47.1 \%$ \\
\hline & Pigeon mesivirus 1 & KC876003 & $38.0 \%$ & $51.6 \%$ & $47.6 \%$ \\
\hline & Goose megrivirus & KY369299 & $32.7 \%$ & $53.8 \%$ & $49.2 \%$ \\
\hline & Goose megrivirus & KY369300 & $36.5 \%$ & $54.1 \%$ & $48.8 \%$ \\
\hline Mischivirus & Mischivirus A1 & JQ814851 & $17.8 \%$ & $28.7 \%$ & $27.6 \%$ \\
\hline Mosavirus & Mosavirus A1 & JF973687 & $17.1 \%$ & $26.8 \%$ & $29.3 \%$ \\
\hline
\end{tabular}




\begin{tabular}{|l|l|l|l|l|l|} 
"Orivirus" & Orivirus A1 & KM203656 & $15.1 \%$ & $24.1 \%$ & $20.8 \%$ \\
\hline Oscivirus & Oscivirus A1 & GU182408 & $14.0 \%$ & $31.2 \%$ & $36.4 \%$ \\
\hline Parechovirus & Human parechovirus 1 & AJ005695 & $14.3 \%$ & $22.2 \%$ & $22.0 \%$ \\
\hline Pasivirus & Pasivirus A1 & JQ316470 & $14.6 \%$ & $26.7 \%$ & $20.7 \%$ \\
\hline Passerivirus & Passerivirus A1 & GU182406 & $15.5 \%$ & $26.1 \%$ & $32.4 \%$ \\
\hline "Poecivirus" & Poecivirus 1 & KU977108 & $26.3 \%$ & $38.4 \%$ & $45.7 \%$ \\
\hline Potamipivirus & Eel picornavirus 1 & KC843627 & $15.0 \%$ & $22.1 \%$ & $20.0 \%$ \\
\hline Rabovirus & Rabovirus A1 & KP233897 & $14.4 \%$ & $28.9 \%$ & $29.1 \%$ \\
\hline "Rafivirus" & Tortoise rafivirus A1 & KJ415177 & $16.3 \%$ & $32.6 \%$ & $32.2 \%$ \\
\hline Rosavirus & Rosavirus A1 & JF973686 & $18.6 \%$ & $33.1 \%$ & $33.3 \%$ \\
\hline Sakobuvirus & Sakobuvirus A1 & KF387721 & $15.3 \%$ & $28.6 \%$ & $38.2 \%$ \\
\hline Salivirus & Salivirus A1 & GQ179640 & $14.3 \%$ & $25.8 \%$ & $32.1 \%$ \\
\hline Sapelovirus & Porcine sapelovirus 1 & AF406813 & $15.3 \%$ & $27.7 \%$ & $28.1 \%$ \\
\hline Senecavirus & Seneca Valley virus 1 & DQ641257 & $16.1 \%$ & $25.9 \%$ & $26.8 \%$ \\
\hline Sicinivirus & Sicinivirus A1 & KF741227 & $14.0 \%$ & $27.8 \%$ & $32.5 \%$ \\
\hline Teschovirus & Porcine teschovirus 1 & AJ011380 & $14.5 \%$ & $24.0 \%$ & $27.0 \%$ \\
\hline Torchivirus & Tortoise picornavirus 1 & KM873611 & $18.9 \%$ & $27.1 \%$ & $30.4 \%$ \\
\hline Tremovirus & Avian encephalomyelitis virus 1 & AJ225173 & $15.1 \%$ & $24.3 \%$ & $18.7 \%$ \\
\hline Unassigned & Quail picornavirus 1 & JN674502 & $16.3 \%$ & $27.2 \%$ & $27.0 \%$ \\
\hline Unassigned & Pigeon picornavirus B & KC560801 & $12.3 \%$ & $27.9 \%$ & $28.2 \%$ \\
\hline
\end{tabular}




\section{Figure legends}

Figure 1.: The coverage and the positions of the metagenomic contigs (ctg 1-3) (A), the genome map with the conserved picornaviral motifs and the predicted P5-P1' cleavage sites. (B), the predicted secondary RNA structure of 5' UTR-IRES (C) and the "Unit A" sequence repeats of the 3' UTR (D) of HaPV-1 strain harrier/MR-01/HUN/2014 (KY488458). Nucleotide (upper numbers) and amino acid (lower numbers in brackets) lengths are indicated in each gene box. The positions of the conserved picornaviral amino acid motifs are indicated with the first amino acid positions of the motif. The main domains H-L were named after the structurally related domains of type-II IRES of EMCV (Yu et al., 2011). The potential eIGF4G-binding site of domain J-K is marked with grey highlight. The nucleotide alignment of "Unit A" repeats (r1, r2) include chicken - (ChMV-1); turkey megriviruses (THV-1), pigeon mesivirus $(\mathrm{MeV}-1)$ and oriviruses $(\mathrm{OrV}-1)$. Conserved regions and identical nucleotides were highlighted with grey and black backgrounds

Figure 2.: Phylogenetic analysis of HaPV-1 (indicated in bold and with an arrow), and the representative members of the family Picornaviridae (P1) and the closest relatives of the study strain (2C and $3 \mathrm{CD}$ trees) based on amino acid sequences of the different picornavirus proteins: $\mathrm{P} 1$ (A), 2C (B) and 3CD (C). Bars indicate amino acid substitutions per site. Members of the megrivirus phylogenetic cluster are indicated with grey boxes. 


\section{Figure 1:}

(A)

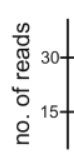

ctg 1

${ }^{15}$

$\operatorname{ctg} 3$

$\operatorname{ctg} 2$

(B)

QVQPQ(779) $\downarrow G \quad N E R R E(1273) \downarrow A$

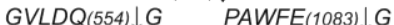

IRNYQ(377)\T
TVSYE(1798) \G

DVEEQ
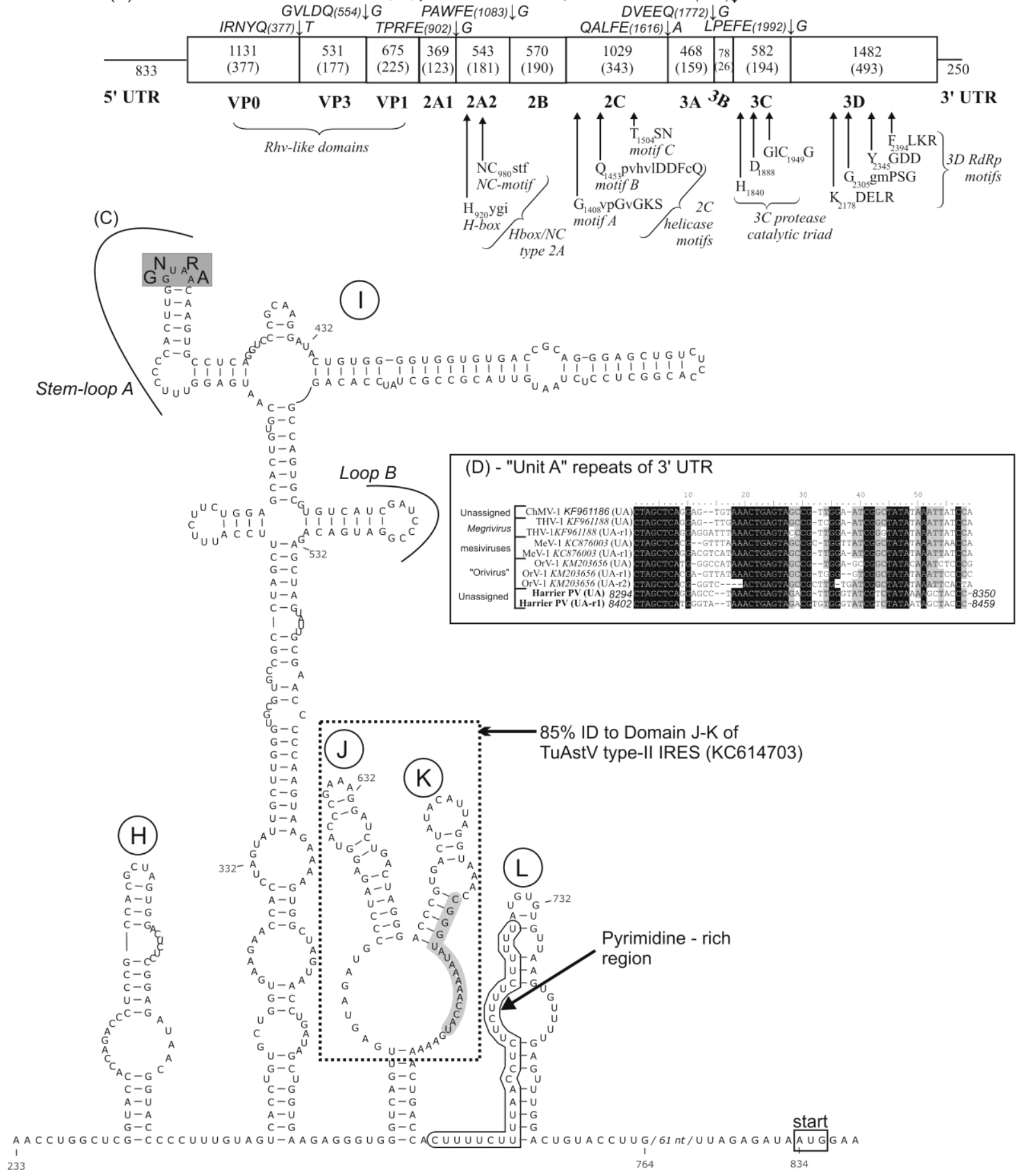


\section{Figure 2:}
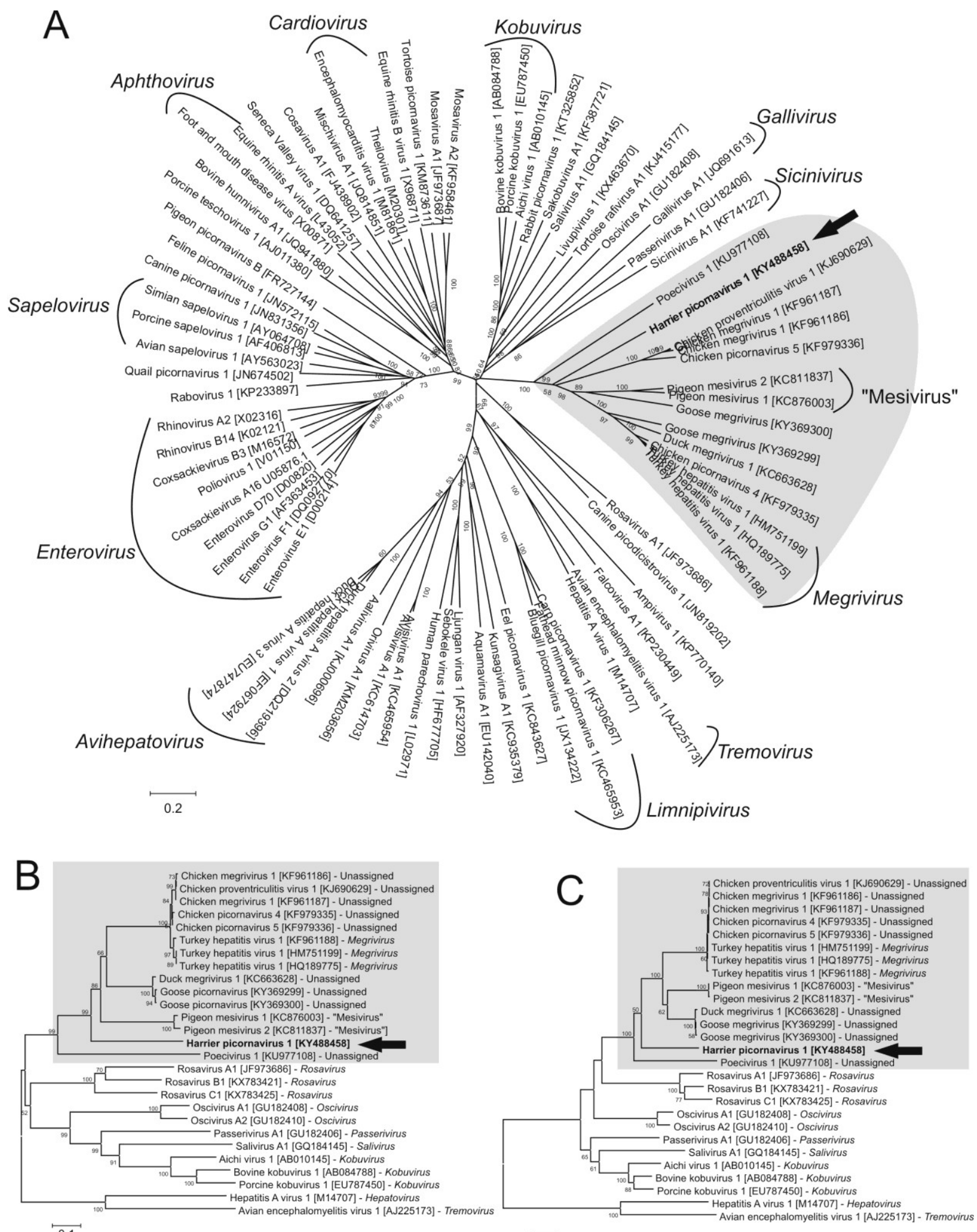